\title{
Preparation and properties of cast polyurethane elastomers with molecularly uniform hard segments based on 2,4-toluene diisocyanate and 3,5-dimethyl-thioltoluenediamine
}

\author{
Xiao-Dong Chen ${ }^{* 1,2}$, Nan-Qiao Zhou ${ }^{1}$, Hai Zhang ${ }^{2}$ \\ ${ }^{1}$ National Engineering Research Center of Novel Equipment for Polymer Processing, The Key Laboratory of Polymer Processing \\ Engineering Ministry of Education, South China University of Technology, Guangzhou, 510640, China; ${ }^{2}$ GuangZhou SCUT Bestry \\ Technology Joint-stock Co., Ltd., South China University of Technology, Guangzhou, 510640, China \\ Email: cxdzlgzhnlg2003@163.com
}

Received 16 December 2008; revised 2 March 2009; accepted 5 March 2009.

\section{ABSTRACT}

A series of three cast polyurethane elastomers were prepared from 2,4-toluene diisocyanate (TDI) and 3,5-dimethyl-thioltoluenediamine (D MTDA) chain extender, with polyethylene adipate (PEA), polyoxytetramethylene glycol (PTMG) and polycaprolactone (PCL) soft segments. The polyol molecular weights employed was $2000 \mathrm{~g} / \mathrm{mol}$. The polyurethane elastomers were characterized by an electronmechanical universal testing machine, an Akron abrasion loss tester, a LX-A Shore durometer, a rebound resilience equipment and a Dynamic- Mechanical analyzer. In addition, fractured surface of the polyurethane elastomers was investigated by a field emission scanning electron microscopy (SEM). The test results showed the PCL based elastomer exhibits the excellent tear and stress-strain properties that polyester based elastomers offer, while retaining superior compression set and resilience similar to polyether based elastomers. The static and dynamic properties of the PCL based elastomer were more suitable for dynamic applications. The SEM micrographs of all polyurethane samples indicated the existing of the microphase separation structure. Particles of the dispersed phase formed by the hard phase and crystalline part of the soft phase grows bigger with the increasing crystallinity of the soft segments. The hard domains are irregular shapes and with the sizes of a few micrometers.

Keywords: Soft Segment; Structure; Cast Polyurethane Elastomer; Properties

\section{INTRODUCTION}

In the recent decades, polyurethane elastomers have been successfully employed in a growing variety of uses and applications, due to their broad range of outstanding properties $[1,2,3,4,5,6,7,8,9,10,11,12]$. The polyurethane elastomers are composed of short, alternating polydisperse blocks of soft and hard segments. The soft segments with a low glass transition temperature are formed generally from polyethers or polyesters, generally of molecular weight 400-5000. The rigid, polar hard segments with a high glass transition temperature are based on diisocyanates and low-molecular-weight chain extenders $[6,13,14,15,16,17,18,19,20,21,22,23,24,25,26,27]$.

Because there exists a degree of thermodynamic immiscibility between the hard urethane segments and the soft polyol segments, polyurethane elastomers exhibit microphase separation, which could result in a structure that can be considered as hard segment domains dispersed in a soft segment matrix $[6,13,21,25,27,28,29,30$, $31,32]$. The resultant two-phase micro-domain structure exhibited by polyurethane elastomers is responsible for their superior mechanical properties. Usually, microphase separation is incomplete and the hard and soft segment phases still contain certain amounts of the other segment. The mean domain size increases from 10 to 20 $\mathrm{nm}$ as the hard segment content increases and the shapes of hard domains are in the form of spheres 5-20 nm, or long needles $5 \mathrm{~nm}$ thick and 50-300 $\mathrm{nm}$ long $[6,14]$.

The two-phase micro-domain structure is greatly influenced by the molecular structure of the diisocyanate, polyol, and chain extender $[13,14,33,34]$, by the ratio of hard segment and soft segment components [35], by the average segment length employed (including molecular weight distribution) [13], by the crosslinking density [18], and by the thermal history of the material [36]. Processing conditions, such as temperature, can also 
change the domain structure significantly [37]. Some researchers have employed many characterization techniques to understand the relationship between the chemical architecture, morphology, and chemical properties $[37,38]$. It is well known that the size, shape, and structure of the hard-segment and soft-segment domains play a crucial role in determination of macroscopic properties [34,39]. Therefore, static and dynamic properties of polyurethane elastomers can be tailored by selecting different diisocyanates, polyols and chain extenders, or by simply varying the processing temperature [40].

In this study, a series of polyurethane elastomers based on polyethylene adipate (PEA), polyoxytetramethylene glycol (PTMG) and polycaprolactone (PCL) with molecular weight of 2000 as soft segments and hard segments based on the combination of 2,4-toluene diisocyanate and 3,5-dimethyl-thioltoluenediamine. In addition to general mechanical properties, resistance to thermal degradation, abrasion and dynamic properties were investigated, and the micro-phase structure images of samples were observed and captured by a Field Emission Scanning Electron Microscope (FE-SEM). The relationship between micro-phase structure and macroscopic properties was discussed. These key engineering properties are considered essential and the obtained results will provide foundation for the formula and structure design of the compounds for various applications, especially for high-loading dynamic applications.

\section{EXPERIMENTAL}

\subsection{Materials}

PEA was obtained form JingXing Polyurethane Co., Ltd. (WuXi, China). PTMG was produced by Mitsubishi Chemical Co., Ltd, Nippon. PCL was purchased from Dow Chemical, USA. The three polyols should be dehydrated in vacuum at $100 \sim 110^{\circ} \mathrm{C}$ for 2 hours before use and their values were described in detail in Table 1. 2,4-toluene diisocyanate, purchased from Qingdao Yutian Chemical Company, was imported in original package and used as received. The chain extender, 3,5-dimethyl-thioltoluenediamine, was purchased Albemarle Company and should be purified by dehydrated in vacuum at $80^{\circ} \mathrm{C}$ for 1 night before use. Dibutyltin dilaurate (DBTDL) was acquired from Atofina Chemicals.

\subsection{Preparation of Polyurethane Elastomers}

Traditionally, polyurethane elastomers can be synthesized via a "one-shot" process or prepolymer method. While the one-shot process is the quickest and easiest of the manufacturing techniques, preparation via the prepolymer method imparts greater control over the chemistry of the reaction, influencing the structure, mechanical properties, reactivity and processability of the finished product $[41,42]$. In this study, the prepolymer method was used. The first stage involves preparation of a prepolymer from the polyol in excess diisocyanate to produce an isocyanate-terminated molecule. Subsequent reaction of the prepolymer with a diol or diamine chain extender constitutes the second stage, which produces a multi-block copolymer.

\subsubsection{First Stage: Preparation of Prepolymer}

2,4 -toluene diisocyanate $(0.83 \mathrm{~mol}, 145 \mathrm{~g})$ was added into a 4-necked round bottom-boiling flask equipped with an overhead mechanical stirring unit, a thermometer and a vacuum take-off/nitrogen inlet. A polyol $(0.37 \mathrm{~mol}, 740 \mathrm{~g})$ was melted in an oven and added to TDI with stirring and reacted at $80{ }^{\circ} \mathrm{C}$ for $2 \mathrm{~h}$ under a nitrogen atmosphere to give a polyurethane prepolymer as a viscous liquid. And the prepolymer was examined for NCO content by using a standard method of n-butyl amine titration.

Table 1. Specifications of the three polyols.

\begin{tabular}{lcccc}
\hline Polyols & Molecular structure of the polyol & $\begin{array}{c}\text { Hydroxyl value, } \\
\text { mgKOH/g }\end{array}$ & $\begin{array}{c}\text { Acid value, } \\
\text { mgKOH/g }\end{array}$ & Molecular weight \\
\hline PEA & $\mathrm{HO}-\left[-\mathrm{CH}_{2}-\mathrm{CH}_{2}-\mathrm{OOC}-\left(\mathrm{CH}_{2}\right)_{4}-\mathrm{COO}-\right)_{\mathrm{n}}-\mathrm{CH}_{2}-\mathrm{CH}_{2}-\mathrm{OH}$ & 56 & $\leqslant 0.5$ & 2000 \\
PTMG & $\mathrm{HO}-\left(-\mathrm{CH}_{2}-\mathrm{CH}_{2}-\mathrm{CH}_{2}-\mathrm{CH}_{2}-\mathrm{O}-\right)_{\mathrm{n}}-\mathrm{H}$ & 56 & $\leqslant 0.02$ & 2000 \\
PCL & $\mathrm{HO}-\left[-\left(\mathrm{CH}_{2}\right)_{5} \mathrm{COO}-\right]_{\mathrm{m}}-\mathrm{R}-\left[-\mathrm{OOC}\left(\mathrm{CH}_{2}\right)_{5}-\right]_{\mathrm{n}}-\mathrm{OH}$ & 56 & $\leqslant 0.05$ & 2000 \\
\hline
\end{tabular}

Table 2. Mechanical properties of elastomers based on different backbones.

\begin{tabular}{lccc}
\hline \multicolumn{1}{c}{ Properties } & PEA-TDI & PCL-TDI & PTMG-TDI \\
\hline $100 \%$ Modulus, MPa & 4.05 & 3.76 & 2.3 \\
$300 \%$ Modulus, MPa & 12.15 & 10.43 & 3.7 \\
Tensile Strength, MPa & 51.15 & 44.09 & 29.86 \\
Elongation at break, $\%$ & 468 & 438 & 380 \\
Tear Strength, KN/m & 69 & 61 & 52 \\
Compression Set, $\%$ & 5.6 & 4 & 4.4 \\
Rebound, \% & 32 & 41 & 44 \\
Hardness, Shore A & 77 & 77 & 78 \\
\hline
\end{tabular}




\subsubsection{Second Stage: Synthesis of Polyurethane} The obtained prepolymer $(200 \mathrm{~g})$ was heated to $80^{\circ} \mathrm{C}$ under vacuum $(<2 \mathrm{~mm} \mathrm{Hg})$. The chain extender $(21 \mathrm{~g})$ was added to the prepolymer. The resultant mixture was stirred at high speed for 60 seconds. If time permitting, the mixture should be degassed (for 1-2 min) to remove the air introduced by stirring. Then the mixture was poured into a pre-heated mold $\left(110^{\circ} \mathrm{C}\right)$. The bubbles on the surface can be removed by sweeping it with a burner flame or with a stream of hot air, what can make the bubbles expanded and bursted. The mold was cured in a vented oven at $110^{\circ} \mathrm{C}$ for 30 minutes. The polymer sheets were demolded and post-cured at an elevated temperature (for $12-16 \mathrm{~h}$ at $110^{\circ} \mathrm{C}$ ). The parts were stored at ambient temperature for 1 month. During this period, secondary chemical reactions should be completely and the microstructure would become established. This is very important for testing the dynamic properties.

\subsection{Characteristics}

The tensile strength and elongation at break were determined with an electronmechanical universal testing machine (INSTRON Co. LTD, Model 5566, USA). The abrasion resistance was performed with an Akron abrasion loss tester. The hardness was tested with a LX-A Shore durometer according to standard method (ISO 481984). The resilience was measured by a rebound resilience equipment (CJ-6A, ShangHai fourth chemical machine factory). The dynamic mechanical analysis was carried out in an air atmosphere by means of a NETZSCH Instrument, Dynamic-Mechanical Analyzer DMA242, on samples of following sizes: $2.0 \times 5.8 \times$ $10.0 \mathrm{~mm}$. The tests at $10 \mathrm{~Hz}$ frequencies, $\pm 2 \mathrm{~N}$ maximum dynamic stress, $\pm 40 \mu \mathrm{m}$ maximum deformation amplitude and the temperature range of $-100 \sim 150^{\circ} \mathrm{C}$, with a heating rate of $5^{\circ} \mathrm{C} / \mathrm{min}$ were accomplished. Fractographs were observed with a Field emission scanning electron microscopy (FE-SEM, Philips XL30 ESEMFEG). Samples were prepared by tearing brittle samples $(0.5 \mathrm{~mm}$ thick) at low temperature by immerging in liquefied nitrogen. All samples were coated with a layer of gold or platinum before characterization.

\section{RESULTS AND DISCUSSION}

\subsection{Influence of the Polyol Structure on the Mechanical Properties of Polyurethane Elastomers}

Table 2 reports a list of some general mechanical properties of a series of the polyurethane elastomers based on PEA, PTMG and PCL as soft segments and hard segments based on the combination of 2,4-toluene diisocyanate and 3,5-dimethyl-thioltoluenediamine. The PEA based elastomer had better tensile strength and elongation, and much better tear resistance compared to the
PTMG based elastomer. However, its compression set and resilience were inferior to the PTMG based elastomer. Interestingly, the PCL based elastomer offered very competitive stress-strain properties and tear resistance when compared with the PEA based elastomer, while significantly improved compression set and resilience over the PEA based elastomer. Its ability to retain elastic properties after prolonged compressive stresses was as good as the PTMG based elastomer, while its resilience performance was close to that of the PTMG based elastomer. From the testing data shown in Table 2, it is clear that the PCL based elastomer possesses more balanced properties. It exhibits the excellent tear and stress-strain properties that polyester based elastomers offer, while retaining superior compression set and resilience similar to polyether based elastomers.

\subsection{Influence of the Polyol Structure on the Phase Morphology of Polyurethane Elastomers}

The SEM method was employed to investigate the morphology of fractured surface of the polyurethane elastomers. As shown in the presented images (Figures 1-3), microphase separation can be observed for all polyurethane samples tested. A continuous phase is visible in SEM micrographs, which is created by the amorphous part of the soft phase and the intermediate phase, i.e., the so-called matrix. Particles of the dispersed phase are encapsulated in that matrix. They are formed by the hard phase and the crystalline part of the soft phase. Three principal thermodynamic factors contribute to the formation of that phase structure: mobility of hard segments, viscosity of the system, and interactions between hard segments [14].

The hard phase and the crystalline part of the soft phase form the so-called domains with irregular shapes and with the sizes of a few micrometers. The size of the domains is mainly dependent on its content of rigid segments and the crystallinity of soft phase, which is clearly visible for the three samples. The soft phase is amorphous in some cases (Figure 2). A small number of tiny particles composed of rigid segments can be observed in the fractured surface only. Crystallization of the soft phase causes the domains bigger in case of the PEA based elastomer (Figure 1) and PCL based elastomer (Figure 3 ). The particle size of the dispersed phase grows bigger with the increasing crystallinity of the soft segments. At the same time, the intermediate phase interface of the PCL based elastomer is much smoother than that of the PEA based elastomer due to its lower degree of crystallinity and less regular arrangement of soft segments. It should be noticed that there are some scratches and cracks in the surface of the PCL based elastomer (Figure 3). We obtained an explanation that the PCL based elastomer had been exposed under 


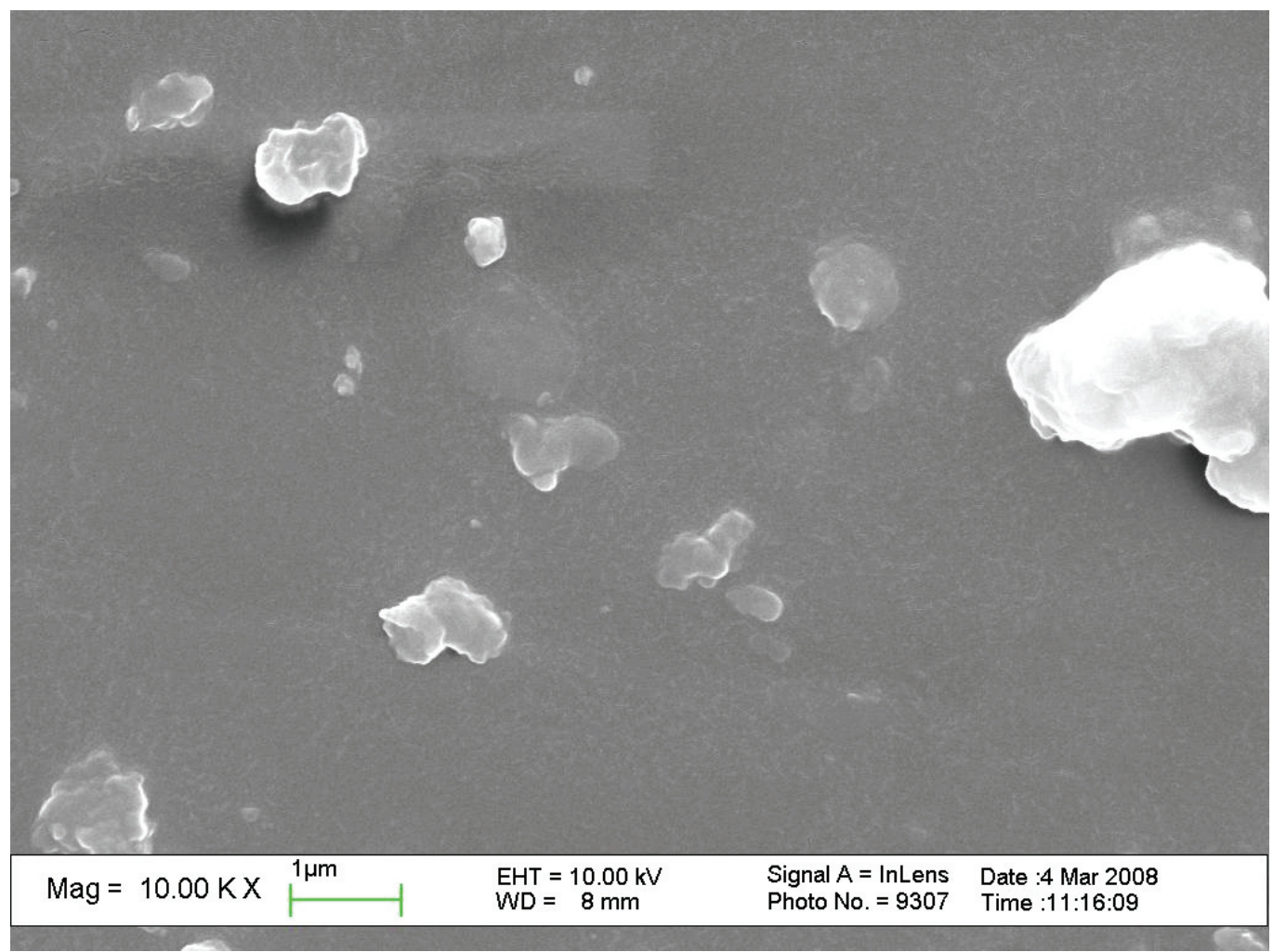

Figure 1. Scanning electron micrograph of the PEA based elastomer.

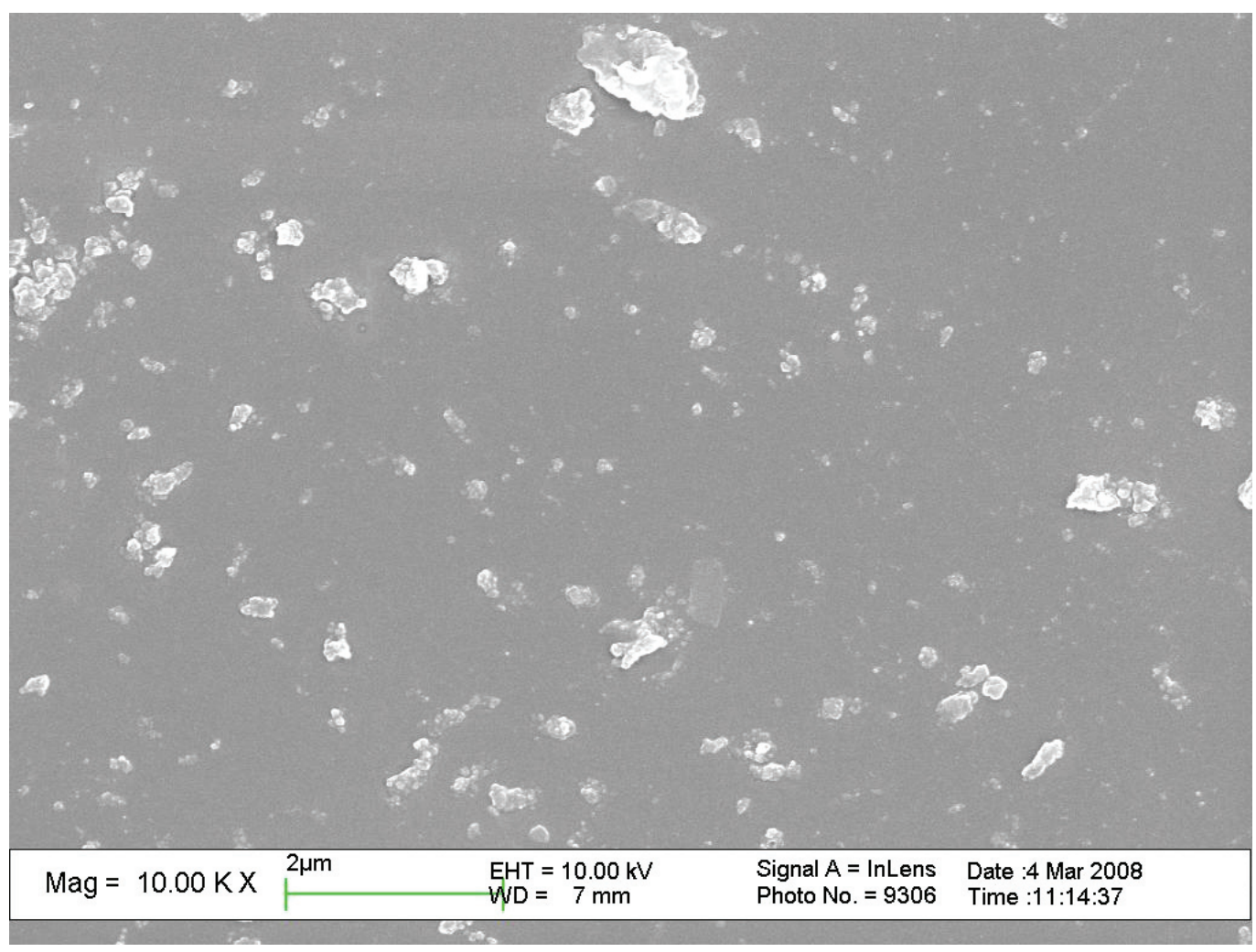

Figure 2. Scanning electron micrograph of the PTMG based elastomer 


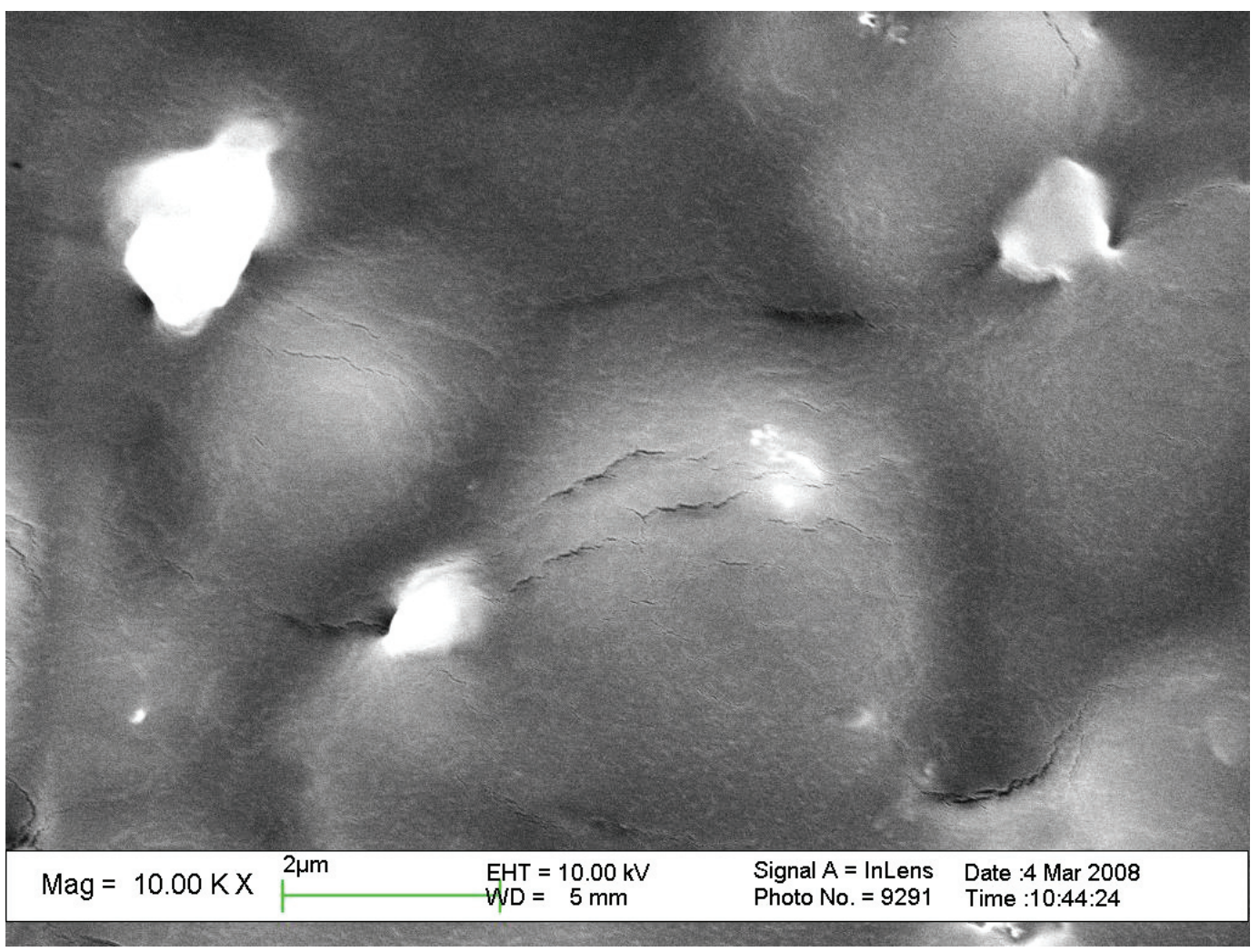

Figure 3. Scanning electron micrograph of the PCL based elastomer.

the electron beam bombardment for certain time after discussed with the SEM operator. It sounds reasonable.

It also should be highlighted that the phase morphology of polyurethane elastomers may be employed to analyze the differences of the mechanical properties of polyurethane elastomers. The differences in microstructure of three polyurethane elastomers could result in the different mechanical properties and abrasion resistances. The hard domains dispersed in that matrix act as the reinforcing carbon black in rubber, so that the polyurethane elastomer with higher microphase separation degree performed better mechanical properties and less abrasion loss than the sample with lower microphase separation degree.

\subsection{Lnfluence of the Polyol Structure on the Thermal Stability of Polyurethane Elastomers}

While a good combination of properties normally suggests toughness of the material, it does not ensure that parts made from such material will survive harsh conditions in the real application environment. As mentioned earlier, polyester based elastomers are generally considered much tougher than polyether based elastomers, however, because the ester linkage is susceptible to hydrolytic cleavage, polyester based elastomers break down rapidly in a hot environment. Therefore, besides general mechanical properties, one may need to carefully examine other factors, such as resistance to thermal degradation and abrasion, when selecting compounds for specific applications.

In Table 3, stress-strain and tear properties of the three polyurethane elastomers before and after aging in air at $120^{\circ} \mathrm{C}$ for 168 hours are listed. It is evident from the data that PCL and PEA based elastomers retained their original stress-strain and tear properties after exposure to high temperature and oxidation, while the PTMG based elastomer lost $40 \%$ to $80 \%$ of its original properties under the same conditions. The results imply that PEA and PCL based elastomers are much more resistant to thermal degradation as compared to the PTMG based elastomer. However, there is no clear evidence that the PEA based elastomer are better than the PCL based elastomer in terms of resistance to thermal degradation, and vice versa.

\subsection{Lnfluence of the Polyol Structure on the Abrasion Resistance of Polyurethane Elastomers}

The abrasion resistance is highly important in applications such as rubber pads for tank track, conveyor belts, mining, pipeline pigs, squeegees, and industry wheels and tires $[7,43,44]$. Table 4 shows Akron abrasion resistance of the three polyurethane elastomers. The data 
Table 3. Tensile Strength and tear properties of elastomers aged at $120^{\circ} \mathrm{C}$ for 168 hours.

\begin{tabular}{ccccccc}
\hline \multirow{2}{*}{ Elastomers } & \multicolumn{2}{c}{ Tensile Strength, Mpa } & \multicolumn{2}{c}{ Elongation at break, $\%$} & \multicolumn{2}{c}{ Tear Strength, KN/m } \\
\cline { 2 - 7 } & Before & After & Before & After & Before & After \\
\hline PEA-TDI & 41.38 & 51.38 & 780 & 946 & 103.25 & 105.26 \\
PCL-TDI & 40.69 & 52.41 & 640 & 730 & 107.63 & 108.55 \\
PTMG-TDI & 37.24 & 7.07 & 570 & 200 & 98.16 & 56.88 \\
\hline
\end{tabular}

Table 4. Abrasion resistance of polyurethane elastomers based on different backbones.

\begin{tabular}{lccc}
\hline Elastomers & PEA-TDI & PCL-TDI & PTMG-TDI \\
\hline abrasion loss, mg & 17.9 & 16.8 & 66.8 \\
\hline
\end{tabular}

indicated that elastomers based on PCL and PEA had similar abrasive resistance, and they are much better than that of the PTMG based elastomer.

\subsection{Lnfluence of the Polyol Structure on the Dynamic Properties of Polyurethane Elastomers}

One important application for polyurethane elastomers is tank track pads, road wheel \& loading wheel flange, many sorts of tires, wheels, rollers and vibration- absorptive materials. In this application, polyurethane elastomers are constantly running at high-speed and under high-load. It is the intrinsic nature of virtually any material to build-up heat while running at high- speed and bearing high-load. Wheels, tires and rollers made from polyurethane elastomers generate heat when they are operating. The buildup of heat can cause failure of urethane parts by melting, tearing, or debonding. Depending on how much heat is generated and how fast the heat is dissipated to the environment, different polyurethane elastomers have different service lifetimes. To improve the service life of polyurethane elastomers in a dynamic environment, we need to improve the dissipation of the heat and select elastomers with improved dynamic properties that can generate less heat, thus run cool for extended time. While the former can be addressed by engineering design of wheels, tires and rollers, the latter has to be resolved from a formulation standpoint.

Dynamic properties of polyurethane elastomers can be analyzed using a Dynamic Mechanical Analyzer. The storage modulus and $\tan \delta$ curves of the polyurethane elastomers based on different backbones are shown in Figure 4 and 5. A good compound for dynamic applications is generally represented by low $\tan \delta$ values and constant modulus values over the working temperature range in which the parts will be utilized. As $\tan \delta=\mathrm{E}^{\prime \prime} / \mathrm{E}^{\prime}$, where $E^{\prime \prime}$ is the loss modulus and $E^{\prime}$ is the storage modulus, a lower $\tan \delta$ value means that energy transferred to heat is much lower than energy stored. Therefore, lower heat buildup occurs in high-speed, high-load bearing applications. Figure 5 shows $\tan \delta$ value for the

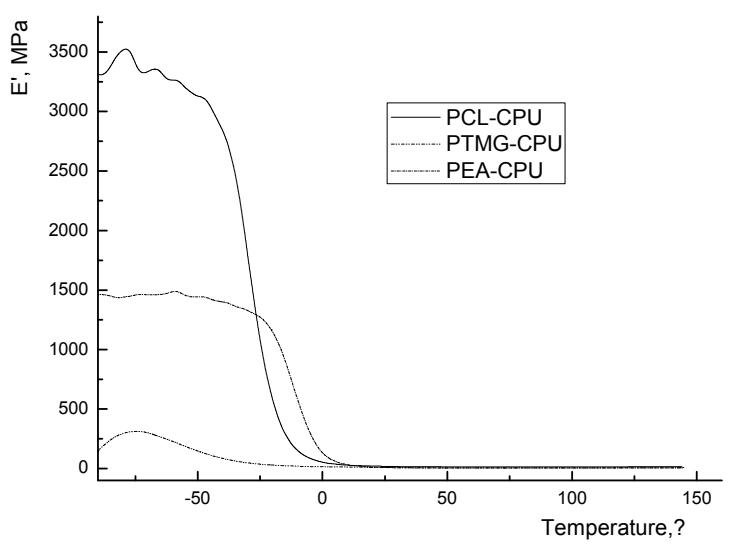

Figure 4. Storage modulus of the polyurethane elastomers based on different backbones.

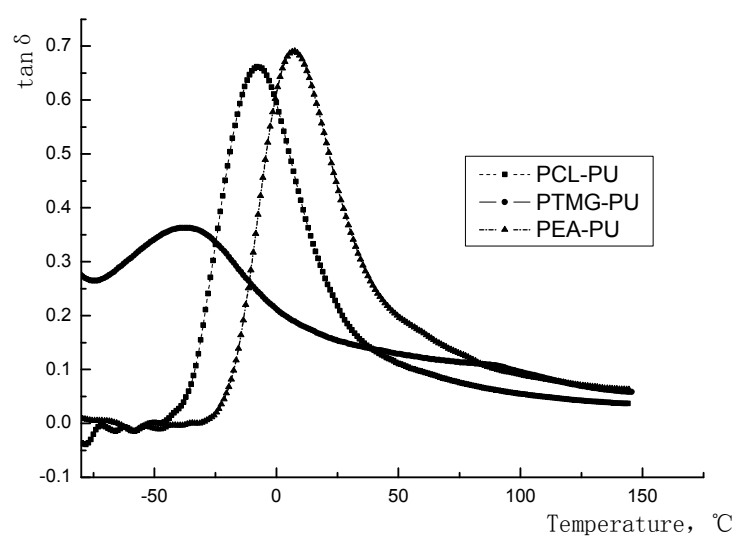

Figure 5. Tan $\delta$ curves of the polyurethane elastomers based on different backbones at temperature range from $-80^{\circ} \mathrm{C}$ to $160^{\circ} \mathrm{C}$.

three polyurethane elastomers in a temperature range from -80 to $180^{\circ} \mathrm{C}$. The tan $\delta$ curves show peaks at low temperature, which is attributed to the glass transition temperatures of the polyurethane elastomers. The tan $\delta$ peak of the PEA based elastomer locates in the higher temperature, this reason maybe the hindered cooperative motion of the polymer chains. The PCL based elastomer had higher $\tan \delta$ value than the PTMG based elastomer at low temperature, but its $\tan \delta$ value was the lowest one among the three polyurethane elastomers at higher temperature (Figure 6). This may stem from the microstructure of the PCL based elastomer. The dispersed phase formed by the hard phase and crystalline part of 


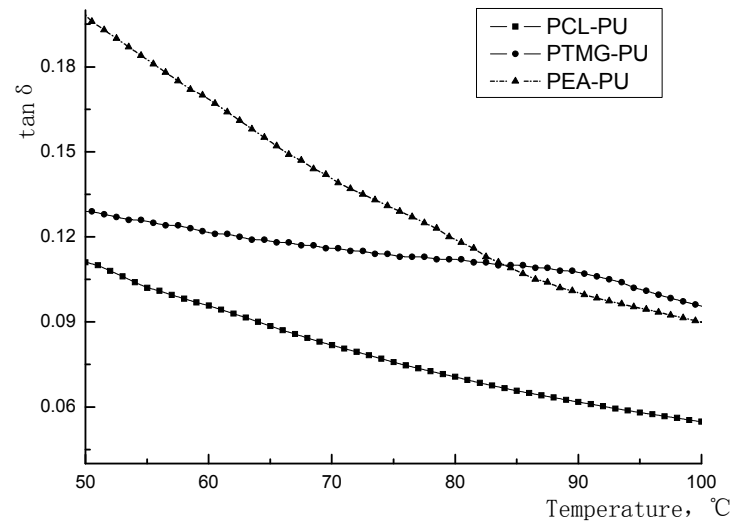

Figure 6. Tan $\delta$ curves of the polyurethane elastomers based on different backbones at operating temperature zone.

the soft phase reinforced the elastomer, and the strong interactions caused by lower degree of soft segment crystallinity and hydrogen bonds enable the motion of the polymer chains more synchronous with the load, which makes the heat build up lower at operating temperature. It is very important for dynamic application accompanied by heat build up that could possibly weaken materials, thus causing failure. Obviously, the PEA based elastomer might not be the best choice for dynamic applications if similar grades of PTMG and PCL based elastomers are readily available. As for PCL and PTMG based elastomers, though the PCL based elastomer has higher $\tan \delta$ value at low temperature, some engineers believe that it is the tan $\delta$ value at higher temperature that really matters. The higher $\tan \delta$ value at low temperature implies that a wheel made from the PCL based elastomer will build up heat faster than a wheel made from the PTMG based elastomer when the wheel is cold. However, as the temperature increases, $\tan \delta$ value decreases. During use, the temperature of the wheel will stabilize at the temperature where heat generated is equal to the heat dissipated, and that will be the operating temperature of the wheel most of the time. This temperature for the PCL based elastomer wheel might be slightly higher than that of the PTMG based elastomer, depending on the engineering design of the wheels. On the other hand, the storage modulus of the PCL based elastomer is the highest one among the three elastomers, this is very helpful for high load application. However, considering the enhanced mechanical strength and resistance to thermal degradation of the PCL based elastomer over that of the PTMG based elastomer, the PCL based elastomer will perform better than the PTMG based elastomer in the field.

\section{CONCLUSIONS}

Three polyurethane elastomers based on different soft segments were prepared and their properties were compared side by side.

The PCL based elastomer exhibits the excellent tear and stress-strain properties that polyester based elastomers offer, while retaining superior compression set and resilience similar to polyether based elastomers.

The SEM results of all polyurethane samples showed the existing of the microphase separation structure. Particles of the dispersed phase formed by the hard phase and crystalline part of the soft phase grows bigger with the increasing crystallinity of the soft segments. The hard domains are irregular shapes and with the sizes of a few micrometers.

As polyester based polyurethane elastomers, PEA and PCL based elastomers are much more resistant to thermal degradation as compared to the PTMG based elastomer.

Polyurethane elastomers based on PCL and PEA had similar abrasive resistance, and they are much better than that of the PTMG based elastomer.

The $\tan \delta$ value at operating temperature zone of the PCL based elastomer is lower than those of the PEA and PTMG based elastomers. And the PCL based elastomer had higher $\tan \delta$ value than the PTMG based elastomer at the temperature around zero centidegree. Based on the time-temperature superposition principle, a conclusion can be made that the PCL based elastomer exhibits good wet skid resistance, low rolling resistance and outstanding dynamic application properties[45,46,47].

In a word, The PCL based elastomer possesses more balanced properties. It is a favorable choice for applications where a combination of engineering properties is desired.

\section{ACKNOWLEDGEMENTS}

This research is funded by the Polyurethane Department of GuangZhou SCUT Bestry Technology Joint-stock Co. Ltd. The authors are grateful to the teacher of National Engineering Research Center of Novel Equipment for Polymer Processing for their helpful advice.

\section{REFERENCES}

[1] S. R. Pajtas, (1990) Polyurethane non-pneumatic tire technology, Development and testing history, in SAE International Congress and Exposition. SAE, Warrendale, PA, USA: Detroit, MI, USA.

[2] L. Stokes and S. Pajtas, (1989) New non-pneumatic polyurethane tire based on innovative technology, Elastomerics, 121, 19-23.

[3] T. M. Madkour and R. A. Azzam, (2002) Use of blowing catalysts for integral skin polyurethane applications in a controlled molecular architectural environment: Synthesis and impact on ultimate physical properties, Journal of Polymer Science Part A: Polymer Chemistry, 40, 25262536.

[4] R. W. Fuest, (2002) Castable polyurethane elastomers- 
Serving demanding engineering applications, Rubber World, 227(39).

[5] C. Hooks, (2005) PU tyre runs cool, smooth, Urethanes Technology, 22(27).

[6] M. Furukawa, K. Ken, and S. Kugumiya, et al. (2008) Microphase separation of bulk and ultrathin films of polyurethane elastomers, Macromolecular Symposia, 267, 9-15.

[7] I. R. Sare, J. I. Mardel, and A. J. Hill, (2001) Wear-resistant metallic and elastomeric materials in the mining and mineral processing industries: An overview, Wear, 250-251, 1-10.

[8] Y. Jiang, Y. Shao, and Q. Zhang (1998) Preparation of tire chain of hot-plasticity type polyurethane elastomer, Fine Chemicals, 15, 57-59.

[9] Z. Wirpsza, (1993) Polyurethanes: chemistry, technology, and applications, Ellis Horwood, London.

[10] V. L. Covolan, R. D. Ponzio and F. Chiellini, et al., (2004) Polyurethane based materials for the production of biomedical materials, Macromolecular Symposia, 218, 273-282.

[11] S. Kutay, T. Tincer, and N. Hasirci, (1990) Polyurethanes as biomedical materials, British Polymer Journal, 23, 267-272.

[12] S. M. Clift, (1991) Understanding the dynamic properties of polyurethane cast elastomers, Journal of Elastomers and Plastics, 23, 66-84.

[13] A. Eceiza, M. D. Martin, and K. Caba, et al., (2008) Thermoplastic polyurethane elastomers based on polycarbonate diols with different soft segment molecular weight and chemical structure: Mechanical and thermal properties, Polymer Engineering and Science, 48, 297-306.

[14] P. P. Barbara, P. Król, and S. Pikus, (2008) Supramolecular structure of crosslinked polyurethane elastomers based on well-defined prepolymers, Journal of Applied Polymer Science, 110, 3292-3299.

[15] H. J. Kogelnik, H. H. Huang, and M. Barnes, et al., (1991) Comparison of the dynamic properties of solid polyurethane elastomers, Journal of Elastomers and Plastics, 23, 314-344.

[16] G. Oertel, (1985) Polyurethane Handbook: ChemistryRaw Materials-Processing-Application-Properties, 2ed edition, Hanser Publishers, New York.

[17] R. A. Assink, (1977) The study of domain structure in polyurethanes by nuclear magnetic resonance, Journal of Polymer Science: Polymer Physics Edition, 15, 59-69.

[18] R. A. Assink and G. L. Wilkes, (1981) Study of domain structure in linear and crosslinked polyurethanes using pulsed proton NMR, Journal of Applied Polymer Science, 26, 3689-3698.

[19] J. N. Gorce, J. W. Hellgeth, and T. C. Ward, (1993) Mechanical hysteresis of a polyether polyurethane thermoplastic elastomer, Polymer Engineering \& Science, 33, 1170-1176.

[20] D. J. Martin, G. F. Meijs, and G. M. Renwick, et al., (1996) Effect of soft-segment $\mathrm{CH} 2 / \mathrm{O}$ ratio on morphology and properties of a series of polyurethane elastomers, Journal of Applied Polymer Science, 60, 557-571.

[21] D. J. Martin, G. F. Meijs, and G. M. Renwick, et al.,
(1996) The effect of average soft segment length on morphology and properties of a series of polyurethane elastomers, I. Characterization of the series, Journal of Applied Polymer Science, 62, 1377-1386.

[22] D. J. Martin, G. F. Meijs, and P. A. Gunatillake, et al., (1997) The effect of average soft segment length on morphology and properties of a series of polyurethane elastomers, II. SAXS-DSC annealing study, Journal of Applied Polymer Science, 64, 803-817.

[23] H. D. Kim, J. H. Huh, and E. Y. Kim, (1998) Comparison of properties of thermoplastic polyurethane elastomers with two different soft segments, Journal of Applied Polymer Science, 69, 1349-1355.

[24] K. S. Chen, T. L. Yu, and Y. H. Tseng, (1999) Effect of polyester zigzag structure on the phase segregation of polyester-based polyurethanes, Journal of polymer science, Part A, Polymer chemistry, 37, 2095-2104.

[25] E. G. Bajsic, V. Rek, and A. Sendijarevic, et al., (2000) DSC study of morphological changes in segmented polyurethane elastomers. Journal of Elastomers and Plastics, 32, 162-182.

[26] B. C. Chun, T. K. Cho, and Y. C. Chung, (2007) Blocking of soft segments with different chain lengths and its impact on the shape memory property of polyurethane copolymer, Journal of Applied Polymer Science, 103, 1435-1441.

[27] P. Król, B. Pilch-Pitera, (2007) Phase structure and thermal stability of crosslinked polyurethane elastomers based on well-defined prepolymers, Journal of Applied Polymer Science, 104, 1464-1474.

[28] K. Ken, S. Nakamura and, M. Furukawa, (2008) Effect of side groups of polymer glycol on microphase-separated structure and mechanical properties of polyurethane elastomers, Journal of Polymer Science Part B: Polymer Physics, 46, 2054-2063.

[29] H. B. Zhang, Y. D. Chen, and Y. C. Zhang, et al., (2008) Synthesis and characterization of polyurethane elastomers, Journal of Elastomers and Plastics, 40, 161-177.

[30] M. Furukawa, Y. Hamada, and K. Ken, (2003) Aggregation structure and mechanical properties of functionally graded polyurethane elastomers, Journal of Polymer Science Part B: Polymer Physics, 41, 2355-2364.

[31] H. Goering, H. Krüger, and M. Bauer, (2000) Multimodal polymer networks: Design and characterisation of nanoheterogeneous PU elastomers, Macromolecular Materials and Engineering, 278, 23-35.

[32] C. D. Eisenbach and W. Gronski, (1983) Hydrogen bonding and phase separation in segmented polyurethane elastomers as studied by 13C NMR magic angle spinning and FT-IR spectroscopy, Die Makromolekulare Chemie, Rapid Communications, 4, 707-713.

[33] K. Madhavan and B. S. R. Reddy, (2006) Synthesis and characterization of poly (dimethylsiloxane-urethane) elastomers: Effect of hard segments of polyurethane on morphological and mechanical properties, Journal of Polymer Science Part A: Polymer Chemistry, 44, 2980-2989.

[34] C. D. Eisenbach, T. Heinemann, and A. Ribbe, et al., (1992) Chain architecture and molecular self-organization of polyurethanes: Perspectives for thermoplastic 
elastomers, Die Angewandte Makromolekulare Chemie, 202, 221-241.

[35] H. S. Xia, M. Song, and Z. Y. Zhang, et al., (2007) Microphase separation, stress relaxation, and creep behavior of polyurethane nanocomposites, Journal of Applied Polymer Science, 103, 2992-3002.

[36] H. C. Jung, S. J. Kang, and W. N. Kim, et al., (2000) Properties of crosslinked polyurethanes synthesized from 4, 4prime-diphenylmethane diisocyanate and polyester polyol, Journal of Applied Polymer Science, 78, 624630.

[37] L. Wu, X. Luo, and X. D. Wang, (2006) Influence of processing conditions on dual-phase continuous blend system of thermoplastic polyurethane with ethylenepropylene-diene monomer elastomer, Journal of Applied Polymer Science, 102, 5472-5482.

[38] C. P. Christenson, M. A. Harthcock, and M. D. Meadows, et al., (1986) Model MDI/butanediol polyurethanes: Molecular structure, morphology, physical and mechanical properties, Journal of Polymer Science Part B: Polymer Physics, 24, 1401-1439.

[39] R. R. Lagasse, (1977) Domain structure and time-dependent properties of a crosslinked urethane elastomer, Journal of Applied Polymer Science, 21, 2489-2503.

[40] C. J. Ong and R. Saxon, (1976) Viscoelastic properties and heat generation in urethane elastomers. Journal of Applied Polymer Science, 20, 1695-1710.

[41] T. O. Ahn, I. S. Choi, H. M. Jeong, et al., (1993) Thermal and mechanical properties of thermoplastic polyurethane elastomers from different polymerization methods, Polymer International, 31, 329-333.

[42] S. Yamasaki, D. Nishiguchi, and K. Ken, et al., (2007) Effects of polymerization method on structure and properties of thermoplastic polyurethanes, Journal of Polymer Science Part B: Polymer Physics, 45, 800-814.

[43] A. I. Hoodbhoy, (1976) Designing with plastics-cast solid-polyurethane industrial tires, Plastics Engineering, 32, 37-38.

[44] I. S. Megna, (1986) Polyurethanes for roll covering, Rubber World, 194, 20

[45] R. Bond, G. F. Morton, and L. H. Krol, (1984) A tailormade polymer for tyre applications, Polymer, 25, 132-140.

[46] A. Lechtenboehmer, H. G. Moneypenny, and F. A. Mersch, (1990) Review of Polymer Interfaces in Tyre Technology, British Polymer Journal, 22, 265-301.

[47] A. M. Shanmugharaj and A. K. Bhowmick, (2003) Dynamic mechanical properties of styrene-butadiene rubber vulcanizate filled with electron beam modified surfacetreated dual-phase filler. Journal of Applied Polymer Science, 88, 2992-3004. 